\title{
Surgical Therapeutic Decision in Cases of Acrylic Resins Use in Achievieng Total Removable Prosthetics
}

\author{
IOAN SARBU ${ }^{1}$, CRISTIAN ADRIAN DINU²*, CRISTIAN CONSTANTIN BUDACU ${ }^{3}$, MIHAELA GABRIELA LUCA ${ }^{4}$, \\ CONSTANTIN MIHAI ${ }^{3}$, CAMELIA ANA GRIGORE², DANA TUTUNARU² \\ ${ }^{1}$ Carol Davila University of Medicine and Pharmacy, 8 Eroii Sanitari Str., 050474, Bucharest, Romania \\ 2Dunarea de J os University of Medicine, 47 Domneasca Str., 800008, Galati, Romania \\ ${ }^{3}$ Grigore T. Popa University of Medicine and Pharmacy, Faculty of Dental Medicine, 16 Universitatii Str., 700115, Iasi, Romania \\ ${ }^{4}$ University of Medicine and Pharmacy, 38 Gheorghe Marinescu Str., 540139, Targu Mures, Romania
}

\begin{abstract}
Materials used in additive techniques are initially in a plastic state to be inserted into different cavities or easily molded (a blunt, for example), after which they pass into a rigid phase. This process is carried out by various methods depending on the material nature. The process can be purely physical (solidifying the alloy melt, the termoplasticized macromolecular compounds), modification and rearrangement of the internal structure (sintering of ceramic masses, crystallization of glasses, amalgam intake), a process of evaporation of some components (lacquers, plasticizing polymers) or a chemical process. This latter process can be an acid-base reaction between two inorganic substances ( $P C Z, C I S$ cements), a chelating reaction (ZOE cements) between a phenolic range (organic compound, usually eugenol or orthoethoxybenzoic acid) and an inorganic powder $(\mathrm{ZnO})$ or a reaction in which a macromolecular compound is formed. After the type of the reaction, the macromolecules are classified into polymers (the formation reaction is called polymerization, the compounds of which are obtained by monomers, the main chain is formed by the carbon atom only), polycondensates (the formation reaction is called polycondensation, the chain also formed from heteroatom-ON, depending on the type of material) or substances that are obtained by polyaddition ( a repeated addition, the mechanism being different from the polymerization. Our study was conducted in the Dental Clinic and comprises a total of 17 patients. The group was represented by patients aged 50-85 years. Clinical observations have been made on cases of fracture of acrylic bases, with the analysis and assessment of some clinical aspects with increased risk of fracture (jaw / mandible, median / paramedian fracture line, etc.), which increase the risk to and fracture when associated. Clinical observations have shown the presence of the risk of fracture in acrylic prostheses, with the need first of all for the proper design and realization of mobile prostheses, but also for the use of inserts.
\end{abstract}

Keywords: Acrylic prostheses, metal inserts, polymers reinforcements, monomer, polymerization, additive techniques, maxillo-facial surgery.

The polymerization is a chemical reaction in which a compound called monomer (M) turns into a polymer (the macromolecular structure, $\mathrm{Mn}$ ), according to the scheme $\mathrm{nM} \rightarrow(\mathrm{M}) \mathrm{n}$, where $\mathrm{n}$ represents the degree of polymerization. In the case of the use of several types of monomers (noted as $A$ and $B$ respectively), the reaction is called copolymerization and the resulting product is a copolymer. The reaction is carried out according to the general scheme: nxA + nyB $\rightarrow$ (AxBy) [1-,3].

The degree of polymerization classifies polymers in oligomers, where $n$ has a value of several units, and high polymers, where $n$ reaches hundreds of thousands. Just the latter are interested in dentistry.

Bakelite was the first plastic of synthesis, invented into by Leo Baekeland in New York in 1907 which also invented the term plastics. Many chemists have contributed to the development of plastic materials science, and through themHermann Staudinger, called the father of polymers chemistry and Herman Mark, called the father of polymers physics.

Most of them plastics are organic polymers, so are consisting of repeating units called monomers (their number may reach several thousand units for every molecule). Depending on the groups nature which have been linked to the main chain of the polymeric molecule, the respective compound have different properties. In In other words, the structure of side chains influences the properties of the plastic [4-6].

During the latest decades have emerged on the market more and more many materials, improved net as compared to precursors, such that preventive restorative therapies can be achieved so much to please the patient, but also to be pleased in particular by the aesthetics of the material and for the doctor's satisfaction, who will remove the problem and will restore the balance at the levelof dental arches.

Acrylic resins are used since long time into the technology to achieve different prostheses. Out of them bases of prostheses are made, artificial teeth or provisional prostheses. These materials are but generating side effects in a large number of patients. In time, there were elaborated new types of acrylic resins or polymers which present favorable characteristics and are compatible with the tissues on which they aggregate.

Self-curing acrylic resins are used in clinical and dental laboratory due to the easy handling [7-12].

The great advantage of the termopolymerizing acrylic resins towards the self-curing stronger is the diffusion of the monomer and crosslinking agent in the thickness of the PMMA beads. The thermoplasticizing acrylic resins 
have a lower residual monomer content, hardness, stiffness and superior strength. Solubility and water absorption are however similar regardless of the type of polymerization. In auto - polymerizable acrylic resins, the polymer powder contains the initiator, and the liquid (the monomer) contains accelerator and inhibitor. The indications of autopolymerizable and heat-polimerizable resins are varied and comprise the base of the partial or total prostheses. The acrylic component has to ensure that the prostheses are kept in the area so that it is aggregated on the extended surface of the soft tissues[13-22].

Repairing the prostheses in time due to overwork, the prostheses may undergo alterations or breaks. If the injury does not require the change of the prostheses, they can be rebated or lined, the work done by the dental technician. Old prosthesis carriers can also experience the change of tissue morphology on which aggregates, requiring optimization of the denture base.

Acrylic resins are used with success with the partial prostheses, too. Many times, or if into the loss of teeth they do not act from time, teeth adjacent the loss breaches will suffer changes and soft subtissues will resorb, phenomena that only complicate the steps subsequent the treatment. Through partial prosthesis the functional inter arcades relations remain.

Acrylic resins keep going to be used on scale range due to a series of benefits they possess in order of economics but also due to acceptable aesthetics.

Acrylic resins dominate the technology of unidentar for decades[22-24].

Out of them were made bases, artificial teeth, faceted and even unidentar or provisional prostheses.

Thermo-polymerizable resins are indicated for the realization of the bases of the total and partial movable prostheses, the repair and optimization of these prostheses, the making of the artificial teeth, the conformers, the gutiers and the gingival prostheses, the mobilizable orthodontic appliances.

Epiminic and polycarbonate resins are used to make unidirectional and semi-permanent prosthesis and polyurethanes are used to make surgical prostheses[2532].

Acrylic resins have been used in stomatology since 1937, which marked the gradual and definitive replacement of vulcanized rubber. The acrylics used for prosthesis bases must have the following biological and physicochemical properties: to be tolerated by the tissues they come into contact with; be stable under all conditions of use, be insoluble, insipid and chemically neutral to all foods and enzymes in the saliva composition, not to exhibit distortion, dilation or contraction at oral or oral occlusion pressures; be abrasion-resistant and brushed for maintenance, be easy to polish, show surfaces without porosity, be of stable chromatic appearance, to be easily manipulated; be easy to repair in case of fracture[33-35].

Methacrylate resin is in the form of liquid and powder. The liquid is represented by methyl methacrylate monomer, or the polymer powder is the form of polymerized methyl methacrylate.

The amount of acrylate required for a total prosthesis is about $150 \mathrm{~g}$ of powder, plus appropriate liquid antitheses. Techniques to achieve the powder and liquid ratio are as follows: weight, volumetric, empirical dosing [36-39].

As the monomer continues its action of dissolving the polymer particles, the paste becomes more and more incoherent, non-sticking, taking the dough appearance.
If the balance of monomer and polymer is not observed, there are a number of inconveniences: the recovery of the acrylic mass shrinkage coefficient, the high percentage of residual monomer, which has toxic action on the tissues, the appearance of the pores both in the thickness of the plate and the saddles, as well as on the surface, with negative effects on mechanical resistance, hygiene and chromatic appearance, the excess of polymer causes the following: reduces plasticity, impedes the introduction of the paste into the pattern, the unevenness of the chromatic appearance of the prosthesis, the low mechanical strength.

Polymerization is a physicochemical reaction in which the monomer joins with the polymer and forms the molecular chain from which a solid body results. Chemically, the polymerization takes place in three stages: initiating, developing and stopping the polymerization[4045].

The polymerization reaction is an exothermic reaction, releasing a temperature of $30-40^{\circ} \mathrm{C}$. The temperature increases with the production rate of the reaction.

The polymerization is carried out in apparatus called polymerizers, which can actin a dry or damp temperature. Because each acrylic resin has its polymerization rules, it is advisable to follow the instructions contained in the leaflet.

There are no differences in the mean values of the bending strength of the four existing resins (Meliodent 66, 23, Trevlon-62,82, Ivocap -68,61, Pro Base Col 61,06 ).

Regarding the hardness of the materials obtained it was found that the polymerization technique has an important influence on it and that with the increase of the pressure there are obtained materials with high hardness[46-55].

Total acrylic denture is a conventional method of prosthesis in the case of total edentation or when there are 1 to 2 arcade arteries remaining. These prostheses have the role of rendering functionality and aesthetic appearance, being the optimal solution for improving the quality of life of patients who have lost their natural teeth. Acrylic resins have been used in dentistry since 1937, which marked the progressive and definitive replacement of vulcanized rubber (the volcanic). From a chemical point of view, acrylates are macromolecular resins derived from acrylic acid, obtained by the polymerisation of several substances derived from the acrylic acid, methacrylic acid and esters of these acids [50]. The metal inserts can be added to the structure of plastics in the form of wire, bars, mesh, nets. The bar and wire reinforcement has been shown to be effective in improving the mechanical properties of the total prostheses in compared to the networks, which have not always provided significant improvements. The position and thickness of the reinforcement within the acrylic mass greatly influences the reinforcement efficiency, the reinforcement must be positioned perpendicular to the anticipated fracture line $[51,52]$.

\section{Experimental part}

\section{Materials and methods}

Our study was conducted in the Dental Clinic and comprises a total of 17 patients. The group was represented by patients aged 50-85. These were represented by 1 male and 5 women in the 55-64age group, 4 males and 2 women in the 65-74 age group and 3 males and 2 women in the last 75-85 year old group (fig.1). 


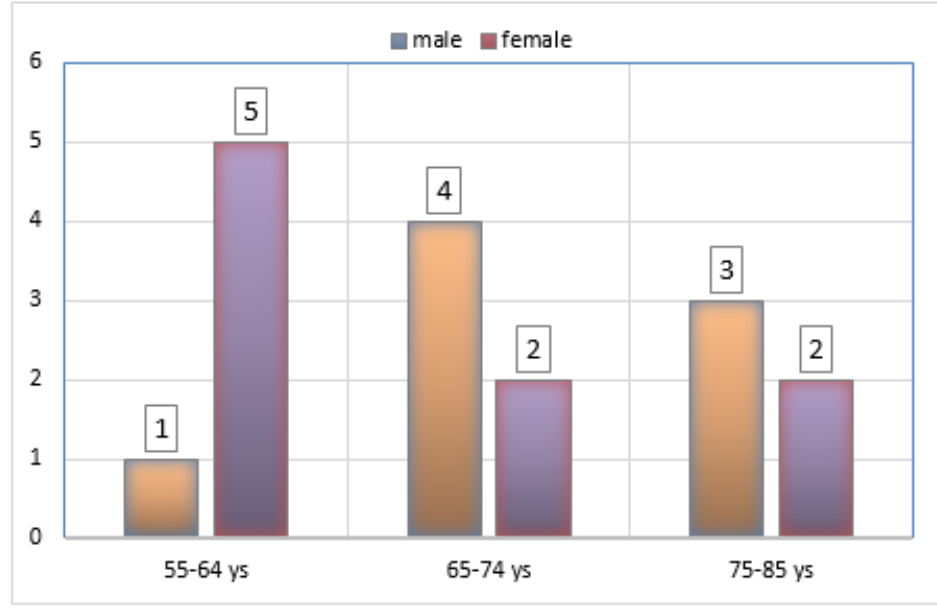

Fig.1 Distribution of group patients according with age

\section{Results and discussions}

The study aims to improve the quality of acrylates used in the field of removable prosthesis.

Excluded from the study were those who could not participate in the study throughout the period; noncooperative patients with psychiatric disorders that influence their ability to understand and observe any treatment; patients with gastrointestinal disorders that have the primary malabsorption effect that may influence the results of parenteral therapy.

Clinical observations have been made on cases of fracture of acrylic bases, with the analysis and assessment of some clinical aspects with increased risk of fracture (jaw / mandible, median / paramedian fracture line, etc.), which increase the risk to fracture. As alternative solutions, glass fiber reinforcement was chosen, making observations on the technique used, the clinical and technical advantages, compared with the reinforcement with metal mesh - 13 cases $(76,47 \%)$, and in 4 cases $(23,53 \%)$ was effected surgery. Surgical trauma in 2 cases $(11.76 \%)$ disturbs the overall neuro-hormonal balance of the body in direct relation to the intensity of aggression and the reactive capacity of the tissue interested in surgical care.

Post- operative disease manifestations, although having a relatively high incidence in dental surgery, and comprises a complex of neuro-vegetative, endocrine, tumoral, circulatory and hemo-leucocytar disorders triggered by the surgical act in the body due to predisposing and favored causes, clinical behaviors being dominated of local phenomena.

The severity of postoperative disease in dental surgery is quite complex as in general surgery, although the surgical wound is often of a much smaller extent.

In oral surgery, postoperative disease has multiple manifestations: edema, inflammation, pain, hematoma, echimosis, trismus.

The continuous training of the practitioner, coupled with experience gained over time, is the premise of a judicious medical attitude.

In 1843 methacrylic acid was discovered. Caspary and Tollens managed to achieve in 1873 the first plastic, acrylic, and in 1924 he their synthesis for use in 1935 to expand improvements in dental practice. These resins suffered multiple days before going to the wide variety of present and remain susceptible to further improvements.

Much used in dentistry are polymerized methyl methacrylate, produced as metal polimethacrylat or PMMA as specified in FDI.
Acrylic resins have dominated decades of dental prostheses technology, including the bases of mobile prostheses, artificial teeth, facets and even unidirectional prostheses (Jacket crowns, inlays), immobilization rails, and so on.

Gradually, however, a number of deficiencies of these materials were noted, especially when they were used to make artificial teeth, unidirectional prostheses and plating. The searches followed in two ways: on the one hand, new types were developed of acrylic resins with improved properties, most of which have the polymerizable methacryloyloxy group (from methyl methacrylate); on the other hand, other polymers have been developed: diacrylics, epoxides, polycarbonates, epiminics, with the intent to emphasize the deficiencies of acrylic resins.

One of the brand-name events that boosted the development of polymers for dental prostheses was launched by Bowen, who developed a new class of polymers based on aromatic dimethacrylates (1958-1962), which can also contain inorganic fillers of the two phases being provided by a coupling agent), thus generating the composite (DRC) resins.

These materials have removed the acrylic resins from the contest in several areas of dental prosthesis, of which only two are mentioned, the artificial teeth and plating materials.

Nowadays, new types of resins have been introduced, unstructured, with a very compact structure. They have high density, high stiffness, hardness and wear resistance, tending to replace even the metallic alloys in some dentures: aesthetic hooks, from resins, orogonal brackets, etc. Such a polymer is polyoxyethylene.

The share of acrylic resins in dentistry is also significant at present, being used for making mobile and movable dentures, artificial teeth, orthodontic appliances, temporary crowns, epithezes, etc.

Dentistry has been revolutionized by the emergence of macromolecular compounds. In its continuous and accelerated development, chemistry and technology of macromolecular compounds has made available for dentistry new materials and techniques of performance, impossible to achieve with classical ones.

Synthetic polymers are used both in the dental office and in the dental laboratory.

Acrylic auto-resins and thermo-polymerizable resins are used to create the bases of movable and mobile prostheses; repair and optimization of mobile and mobile prostheses; surgical prostheses; artificial teeth, conformers, gingiva and gum prosthesis; unidentar prostheses and temporary bridges, orthodontic appliances. 
Composite diacrylic resins (CRDs) have superior properties, lower polymerization shrinkage, higher physicomechanical, chemical and electrical strength, better thermal and physico-chemical characteristics (unidirectional prostheses, dental bridges, plating materials, etc.).

The epiminic resins, the structure of which resembles epoxydic resins (the oxy-atom of the epoxide ring has been replaced with the imine-NH group) have the degree of polycondensation $n$. They are self-polymerizable and are used to make temporary prostheses.

Polyamide resins with good mechanical strength but a low modulus of elasticity.

Polyamides have polymers resulting from the condensation of a diacid with a diamite, resulting in a variety of reaction products whose physical and mechanical properties depend on the groups which crosslink the acidic or amine radicals.

The first type of nylon used to make teeth was a failure because the chosen type absorbed excessive water, resulting in some degree of plasticization and even biodegradation of the material. The introduction of reinforced glass nylon gave encouraging results. This type of material is engraved with glass particles or filaments, providing a few more rigidity compared to glass beads, being close to the rigidity of thermo-PM PMMA.

One of the advantages of polyamide resins as prosthetic materials was their good mechanical strength and bending, but very quickly the disadvantages of these resins were observed: the low modulus of elasticity; reduced storage capacity of shape and volume; obvious chromatic changes; poor clamping and holding ability of teeth and hooks; handling and their technology requires complicated equipment.

Polycarbonate resins are derived from carbonic acid condensation, have a dense structure and physicomechanical properties superior to acrylic resins; are processed by injection; are used for the industrial manufacture of temporary crowns.

Polyoxiomethylene resins or acetal homopolymers are obtained by polymerizing formaldehyde and have crosete indications for partial prostheses, crowns and temporary bridges, adhesive bridges, artificial teeth, orthodontic appliances, skeletal prostheses, partial prostheses, total prostheses, etc.

Nowadays, the properties of polymers used in making the bases of total or partial prostheses are improved in at least three directions: providing radioactivity of the material; increasing impact resistance; increasing stiffness.

Photopolymer combination of diacrylic resins - The quantity of diacrylic resins in the manufacture of dental prostheses has increased dramatically, particularly with regard to the unidental dentures: inlays, crowns mixed, onlays, crowns or bridges jacket (crowns) not permanent. The origin of these materials is closely related to the name Dr. Castang, who synthesized in 1936 an epoxy resin, of which he intended to make artificial teeth.

Epoxy resins have been the starting point for obtaining the most important polymers used in the dentistry of our century, the composite diacrylics.

After Dr. Castang's failure, the first success in this field is Bowen's, who, between 1957 and 1962, working at the National Bureau of Standards in the United States, has set up a monomer on which various types of synthesis of diacrylic resins.

The diacrylic resins have a lower contraction in polymerization; low thermal expansion, low water absorption (between $0.13 \%$ and $1.7 \%$ compared to $2 \%$ for PMMA); superior mechanical performance (resistance to compression, bending, etc.) to PMMA, physico-chemical adhesion to the metal frame, while the PMMA metal bond is only macromechanic; wiped out phenomena, great physiognomic effects, much improved compared to PMMA; chromatic stability in time, relatively good.

From a chemical point of view, the organic matrix is a dimethacrylate urethane cracked with pyrolytic silica, acrylic beads, and high molecular weight acrylic resin monomers.

Metal inserts: since the 1960s, reinforcement of orthodontic appliances with mesh, wire or stainless steel plates has been practiced. A single and thick reinforcement provides strength and rigidity, but the discontinuity it produces in the relief of the prosthesis is uncomfortable and undesirable. Therefore, two or more reinforcements, of reduced thickness and spacing of several millimeters are preferred.

The reduced adhesion between metallic particles and polymer is the underlying problem of many failures to reinforce acrylate. In order to improve this adhesion, various techniques for conditioning metallic particles, such as templates, silanization, and the use of different adhesive resins, have been promoted. The rust thus obtained has a beneficial effect on the fracture resistance of the parts.

The best results were obtained after the stitching, the retention betw een the reinforcement and the resin being improved by the increased interference between the two materials. The use of a 4-Meta type adhesive also had positive results in increasing the adhesion between inserts and resins. Another method of conditioning the metal inserts is silanization, its effectiveness being demonstrated by increasing the fracture resistance of the acrylate-metal structure.

Kevlar fibers have a very high-90Cpa rigidity, have a lightstraw color, they are light and very resistant. Polymer (PMMA and Bis-GMA) polymer with such fibers results in a spectacular increase in mechanical properties. For that they make an unaesthetic appearance, their use is restricted to the oral faces of artificial teeth and total prostheses.

Carbon fibers give composite materials a fracture resistance and high rigidity. Carbon fiber reinforcement dental prosthesis requires a longer working time than classical PMMA base prostheses. The presence of carbon fiber reinforcement greatly increases fatigue and flexural strength (more than $70 \%$ ) and Torsion (more than $50 \%$ ).

The results of the experiments confirm the important improvement of the mechanical properties of the resins after they were reinforced with carbon fibers.

Perma Fiber are revolutionary glass fibers, due to the fact that each fiber is impregnated with a computer with acrylic resin (porous polymer) and silane, allowing for a strong bond with all acrylic resins. Glass fibers are recommended to be a simple technique with wide possibilities of use, leading to composites with physical characteristics superior to simple acrylates.

Appropriate adhesion of the fibers to the polymer matrix is the most important factor in obtaining increased hardness. The creation of this bond requires proper impregnation of the fibers, and once this bond is obtained, it creates the possibility of obtaining a smooth surface by polishing, thus eliminating the possibility of irritation of the tissues.

Materials that create a chemical bond have a hardness of 100 times greater than non-armed materials. This is due to the elimination of voids between the acrylic resin and reinforcement. Kevlar polyethylene fibers, metal nets, 
do not create such a good bond with acrylic resins. Appropriate adhesion to the polymer matrix of fibers is the most important factor in obtaining the hardness. Creating the bond requires proper fiber moistening $[56,57]$.

There are polyethylene fibers, vinyl polymers made of ethylene, which may have a branched or linear structure. Linear-structure fibers have a higher degree of flexibility and hardness than branched, and because of their dense structure, they have higher resistance to stresses.

Ribbond fibers prevent fractures of composite and acrylic resin work, and the dentures retain the same properties as the beginning for a longer period. The unique combination of Ribbond fibers makes a very good bond and their structure increases the hardness and fracture resistance of the prostheses. These fibers are made of polyethylene fibers.

Total prosthesis offers multiple benefits: patients can chew much better and more diverse foods, improve pronunciation, prosthesis is a support for lips and cheeks, eliminating the specific aging effect of patients without teeth, maintaining the health of the gums and jaw.

\section{Conclusions}

With a wide range of acrylic resins available today, clinicians can benefit from knowing the infrastructure of a particular material in order to determine which type will work best in a specific clinical situation.

The polymerization pressure regime does not increase the bending strength, which has close values for the four acrylic resins.

\section{References}

1.*** American Chemical Society National Historic Chemical Landmarks.Bakelite:The World's First Synthetic Plastic. accessed into the February 23, 2015.

2.EDGAR, DAVID; EDGAR, ROBIN (January 1, 2009). Fantastic Recycled Plastic: 30 Clever Creations to Spark Your Imagination. Sterling Publishing Company, Inc. - via Google Books. 3.TEEGARDEN , DAVID M. ( January 1, 2004). \& Quot; Polymer Chemistry: Introduction to an Indispensable Science \& quot; . NSTA Press - via Google Books.

4.EBBING, DARRELL; GAMMON, STEVEN D. (January 1, 2016). General Chemistry (in English). Cengage Learning. ISBN 9781305887299 .

5.*** Classification of Plastics archived 2007-12-15 at Wayback Machine .. Dwb.unl. edu. Retrieved on 2011-07-01.

6*** Nereciclat, plastic killing nature,24 J une 2010, evz.ro, accessed on August 18, 2010.

7.ANTOHE M, ANDRONACHE M, GIRBEA G, FORNA N Silicone materials versus acrylic materials in mobilizable prosthesis, MedicoSurgical Review, International Congress of Medicine Dental, April 2328, 2007, 330,335.

8.AODA K, SHIMAMURA I, TAHARA Y, SAKURAI K. - Retainer design for unilateral extension of partial partial removable dental prosthesis by three-dimensional finite element analysis. JProsthodont Res. 2010 J an 28

9.***Applegate CO-An evaluation of the support for removable denture, J.prosth.Dent . 1960, 10, 112-117

10.ARMELLINI DB, HEYDECKE G, WITTER DJ , CREUGERS NICO HJ - Effect of removable partial dentures on oral health related quality of life in subjects with shortened dental arches: a 2-centercross sectional study, The International J ournal of Prosthodontics, 2008 Nov-Dec

11.ARMELLINI DB, HEYDECKE G, WITTER D J, CREUGERS NHJ Effects of removable partial dentures on the quality of life in people with shorteneddental arches; Nederlands tijdschrift voortandheelkunde, 12 -2009
12.BRATU D, BRATU E, ANTONIE S - Restoration of partial edentations by mobilizable prostheses, Publishing house Medical , Bucharest, 2008

13.BROSH T, BEN UR Z, SHERSHEVSKY A, MIJIRITSKY E-Mechanical behavior of major connectors-Part 1: Influence of supporting tissues, Refuat Hapeh Vehashinayim, 2007-01 Tel Aviv, Israel

14.Brudvik JS, Palacios R - Lingual retention and the elimination of the visible clasp arm, J ournal of Esthetic and Restorative Dentistry : Official Publication of the American Academy of Esthetic Dentistry , 2007.

15.Creugers NHJ, by Baat C - Removable partial dentures. Oral functions and types, Nederlands - tijdschrift voor tandheelkunde , 2009-11

16.Forna N, Antohe M- Substance Loss Rehabilitation, Ed. Demiurg , 2007, ISBN 978-973-152-035-3

17. Forna N- Dental medicine between reality and paradigm, Ed. Demiurg, 2008

18. Heydecke G, Butz F, Binder JR, Strub JR - Dental Materials, Vol. 23(2007) p.785-791.

19.HIRABAYASHI M, MOTOYOSHI M, ISHIMARU T, KASAI K, NAMURA $S$-Stresses in the mandibular cortical bone during mastication: biomechanical considerations using a three-dimensional finite element method. Department of Orthodontics, Nihon University School of Dentistry, Tokyo, Japan.2008.

20.J OHANSSON A, UNELL L, J OHANSSON AK, CARLSSON GE - A 10year longitudinal study of selfassessed chewing ability and dental status in 50-year-old subjects. The International Journal of Prosthodontics, 2007.

21.KOVAEEVIC PAVICIC D, DELIC Z, LAJ NERT V, FUGOSIC V, SIMONIC KOCIJAN SUNCANA B - Changes of alveolar bone density around abutment teeth in patients wearing removable partial dentures depending on Kennedy classification. Journal Collegium antropologicum 12-2009.

22.LEE G, ENGELMEIER RL, GONZALEZ M, POWERS JM, PEREZOUS LF et al. - Force Needed to Separate Acrylic Resin from Primed and Unprimed Framew orks of Different Designs, J ournal of Prosthodontics, January 2010

23. NICULESCU,O.,NICA,P., GURLUI,S.,et al., Experimental investigations of polymer plasma laser ablation, Mat. Plast.46, no. 3, 2009,p.336-338

24. VASLUIANU, E.,POPESCU, V., GRIGORIU,A., et al., Comparative study concening the FIR Analysis and the performances of chitosanbased wrinkle-proofing agents, Rev. Chim. (Bucharest), 64, no. 10, 2013, p.1104-1115

25. NASH,D.,RUOTOISTENMAKI, ., ARGENTIERI,A.et al., Profil of the oral healhcare team in countries with emerging economies,Conference Global Congress on Dental Education location, Dublin,Ireland, European J ournal of Dental Education, 12((1), 2008, pg.111-119

26. POPESCU,V., VASLUIANU,E., FORNA,N.C., et al., Comparative study of the FTIR Analysis and the peformances of N,N,N-trimethyl chitosan as wrinke-poofing agent, Rev. Chim. (Bucharest),64, no. 11, 2013, p.1284-1294

27. BELEI D., FORNA N.C.,SANDU I., et al.,Novel Mesoionic 2-Methyl14-(1,3-Dithiol-2-yllum) phenolates, Rev.Chim. (Bucharest), 65, no.1,2014, p.80-83

28.ANTOHE, M.E., FORNA AGOP, D., DASCALU, C.G., Implications of digital image processing in the paraclinical assessment of the partially edentated patient, Rev. Chim. (Bucharest), 69, no. 2,2018 p.521-524 29. CIOCAN-PENDEFUNDA A.A., MARTU, M.A., ANTOHE M.E., et al.,Romanian J ournal of oral rehabilitation,, 10(4), 2018,pg.91-96,

30.ANCUTA,C., POMIRLEANU, C., IORDACHE, C., etal., Serum lipid profile in diffuse versus limited systemic sclerosis data from the SASS cohort, Rev. Chim. (Bucharest), 69, no. 2, 2018, p.403-406

31.IORDACHE, C., GHIORGE,C.A., ANTOHE M.E., et al., Temporomandibular joint involvement in rheumatoid arthritis and ankylosing spondylitis:a cross-sectional study, 994),2017,pg.40-46 
32.INDREI, L.L., RAFTU, G., DEBITA, M.,et al., The role of chemical substances in the assessment of the hygenic and sanitary conditions from medical practices, Rev. Chim. (Bucharest), 70, no. 2,2019, p.700-704 33. POPA, C., STELEA, C.G., FILIOREANU, A.M., et al., PCR Analysis of the Herpesviruses presence in crevicular fluid in HIV-positive patients, Rev. Chim. (Bucharest), 68, no. 11, 2017, p. 2672-2675

34. FORNA AGOP ,D., POPESCU, E., COSTAN V.V., et al.,Conventional maxillary reconstruction using service obturators, Romanian Journal of Oral rehabilitation,(8),3,2016, pg.32-39

35.DASCALU, C.G., CARAUSU, E.M., MANUC, D., Methods for Data Selection in Medical Databases: The Binary Logistic Regression Relations with the Calculated Risks, Proceedings of world academy of science, engineering and technology, VOL 28, Book Series: Proceedings of World Academy of Science Engineering and Technology Volume: 28 Pages: 278-+ Published: 2008

36.EARAR, K., ANTONIAC, V.I., BACIU, S., et al, Etching treatment effect on surface morphology of dental structures, Rev. Chim. (Bucharest), 68, no. 11, 2017, p.2700

37. JUMANCA,D., GALUSCAN,A., PODARIU,A.C., et al., Antiinflammatory action of toothpastes conaining betulin nanocapsules, Rev. Chim (Bucharest),65, no. 12, 2014, p.1473-1476

38. SAVIN, C., ANTOHE M.E., BALAN, A., et al., Study regarding the elastic impression biomaterials dimensional stability, Rev.Chim. (Bucharest), 70, no. 3, 2019,p.797-800

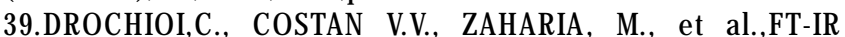
Characterization of some biological materials used in reconstructive surgery, Rev. Chim. (Bucharest), 66, no. 9, 2015, p. 1302-1305

40.ASAFTEI,I.V., EARAR, K., BIRSA,L.M. et al. Conversion of light hydrocarbons with butanes from petroleum refining processes over Zn-HZSM-5 and Zn 0/HZSM-5 catalysts, Rev. Chim.(Bucharest), 66, no. 7, 2015,p.963-971

41.HRISTIAN, L.BORDEIANU,D.L., IUREA,P., et al Study of the tensile properties of materials destined to manufacture protective clothing for firemen, Mat. Plast., 51, no. 4, 2014, p.405-409

42.LEAVES CR, MARTINS RR, SILVA ET, NUNES MF - Discriminant analysis of patients' reasons for choosing or refusing treatments for partial edentulism , J ournal of oral rehabilitation, 2009-12

43.NEO TK, SEN-HO K, CHENG A Functional reconstruction and aesthetic management of the anterior maxillary segment; Cosmetic dentistry, no.1, February 2009, pp. 32-35

44.OH WON- SUK, SAGLIK B - Provisional Prosthetic Management of Mobile Teeth in conjunction with the Removable Partial Denture Using Wire Orthodontic Journal of Prosthodontics, 2009

45.OHLMANN B ROHSTOCK K, KUGLER J GILDE H, DREYHAUPT J, STOBER T - Influences on wear of acrylic denture teeth Clinical: a pilot study, The International J ournal of prosthodontics, 2007 septOctober
46.PATEL MB, BENCHARIT S., A treatment protocol for restoring occlusal vertical dimension using an overlay removable partial denture as an alternative to extensive fixed restorations: a clinical report, Open Dent J. 2009 Oct 30; 3: 213-8

47.PIENKOS TE, MORRIS WJ, GRONET PM, CAMERON SM, LOONEY SW - The strength of multiple major connector designs under simulated functional loading, The Journal of Prosthetic Dentistry, 2007-05

48.SATO Y, SHIMODAIRA O, KITAGAWA N - Systematic clinical evaluation and correction procedures for the support of removable partial dentures. Journal of Prosthodontics: Official Journal of the American College of Prosthodontists, 2008-04

49.TRAN C, LABARRE E, LANDESMAN HM., A removable partial denture using an esthetically designed round-resting distal clasp on the maxillary anterior abutment teeth: a clinical report. J Prosthet Dent. 2009 Nov; 102 (5): 286-9.

50.FLORESCU, L, TEMNEANU, OR, MINDRU, DE., Social and Medical Implications of Teenage Motherhood. REVISTA DE CERCETARE SI INTERVENTIE SOCIALA 52, 2016, pp. 80-91

51.MINDRU, DE, STANESCU, RS, MATEI, MC, DUCEAC, LD, RUGINA, A, TEMNEANU, OR, UNGUREANU, M, FLORESCU L. Stress in pediatric patients - the effect of prolonged hospitalization. MEDICAL-SURGICAL JOURNAL-REVISTA MEDICO-CHIRURGICALA, 120, 2016, no.2, pp. 417423.

52.MINDRU, DE, MATEI, MC, RUGINA, A, CIOMAGA, IM,NISTOR, N, FLORESCU, $L$. The informed consent in pediatrics - a child's right. MEDICAL-SURGICAL J OURNAL-REVISTA MEDICO-CHIRURGICALA, 123, 2019, no.1, pp.153-160.

53.Van LOVEREN C - Prevention: the success of a partial denture, Nederlands tijdschrift voortandheelkunde , 2009-11

54.PALADE, DO, COBZEANU, BM, ZAHARIA, P, DABIJA, M. 3D Reconstruction Role in Surgical Treatment of Sinonasal Tumours. Rev Chim (Bucharest), 69, no.6, 2018, p. 1455-1457

55.VERRI FR, PELLIZZER EP, MAZARO J V,ALMEIDA EO, ANTENUCCI RM - Esthetic intermediate acrylic resin reinforced with metal casting. J Prosthodont. 2009 Aug; 18 (6): 541-4. Epub 2009 J un . 56.AGHEORGHIESEI DT, DABIJA, M, COPOERU, I. An ethical approach to accreditation standards for hospitals in romania. The need for ethics audit to improve the quality of care for patients. REVISTA ROMANA DE BIOETICA, 12, 2014, no.2, pp.70-83.

57.LUPASCU C, DABIJA M, URSULESCU C, ANDRONIC D, VASILUTA C, URSARU M. Removal of an Intraperitoneal Foreign Body Using a Single Port Laparoscopic Procedure. J SLS-J OURNAL OF THE SOCIETY OF LAPAROENDOSCOPIC SURGEONS, 15, 2011, no.2, pp. 257-260.

Manuscript received: 12.05 .2019 